Азиатско-Тихоокеанский регион: экономика, политика, право. 2021. Т. 24, № 4. С. 111-131. Pacific Rim: Economics, Politics, Law. 2021. V. 24, No 4. P. 111-131.

\title{
ПОЛИТИКА
}

Научная статья

УДК 327(5:265)

https://doi.org/10.24866/1813-3274/2021-4/111-131

\section{КОНЦЕПЦИЯ СВОБОДНОГО И ОТКРЫТОГО ИНДО-ТИХООКЕАНСКОГО РЕГИОНА: ОБЩЕЕ В МНОГООБРАЗИИ ИНТЕРПРЕТАЦИЙ}

\section{Сергей Константинович Песцов}

Центр глобальных и региональных исследований ИИАЭ ДВО РАН, 690091, Россия, Владивосток, ул. Пушкинская, 89г, skpfox@yandex.ru

Аннотация. В настоящее время Индо-Тихоокеанский регион (ИТР) всё более очевидно превращается в один из популярных концептов, которые используются для характеристики и описания новых трендов в современной мировой политике. Как географический термин он призван очертить границы формирующегося интеграционного пространства. В содержательном плане он представлен многочисленными вариациями «Свободного и Открытого Индо-Тихоокеанского региона (FOIP), отражающими видение региона разными акторами. Эти видения совпадают далеко не во всём и не всегда. В этой связи особую актуальность приобретает вопрос, касающийся наличия общих черт, позволяющих, при всех различиях в национальных интерпретациях, говорить о наличии / формировании согласованного содержательного ядра идеи FOIP. Прежде всего это касается четырёх основных акторов - США, Японии, Австралии и Индии - как инициаторов и наиболее последовательных сторонников концепции Индо-Тихоокеанского региона. Сравнение их подходов уже сегодня позволяет говорить, как минимум, о трёх основных столпах формирующейся единой концепции FOIP, каковыми являются (а) обеспечение мира и стабильности; (б) утверждение и защита фундаментальных ценностей; (в) интенсификация сотрудничества и содействие экономическому развитию. Данное исследование начинается с введения, которое содержит краткое обоснование важности дифференциации ИТР как географического понятия и содержательной концепции.

(С) Песцов С. К., 2021 
Основная часть исследования посвящена анализу практики текущих региональных взаимодействий ключевых акторов и оценке перспектив формирования общей согласованной стратегии. В заключении отмечается, что несмотря на различия в интерпретациях географических рамок ИТР, есть все основания говорить о начале рождения нового согласованного геополитического его понимания, представленного формулой «Свободного и открытого Индо-Тихоокеанского региона (FOIP)».

Ключевые слова: международные отношения, регионализм, Индо-Тихоокеанский регион, Свободный и открытый Индо-Тихоокеанский регион, безопасность, экономическое сотрудничество, интеграция, связанность, США, Япония, Индия, Австралия, Китай.

Для ичитирования: Песцов С. К. Концепция свободного и открытого ИндоТихоокеанского региона: общее в многообразии интерпретаций // АзиатскоТихоокеанский регион: экономика, политика, право. 2021. Т. 24, № 4. С. 111-131. https://doi.org/10.24866/1813-3274/2021-4/111-131.

\section{POLITICS}

Original article

\section{THE CONCEPT OF A FREE AND OPEN INDO-PACIFIC REGION: THE COMMON GROUND IN A VARIETY OF INTERPRETATIONS}

\section{Sergey K. Pestsov}

Center for Asia-Pacific Studies, Institute of Archeology and Ethnography, Far Eastern Branch of the Russian Academy of Sciences, 89 Pushkinskaya St., Vladivostok, Russia; skpfox@yandex.ru

Abstract. The Indo-Pacific Region (IPR) is increasingly becoming one of the popular concepts used to characterize and describe new trends in modern world politics. As a geographical term, it is intended to outline the boundaries of the emerging integration space. In terms of content, it is represented by numerous variations of the Free and Open Indo-Pacific (FOIP) region, reflecting the vision of the region by different actors. These visions do not always coincide in everything. In this regard, the issue of the presence of common features that allows, with all the differences in national interpretations, to speak about the presence / formation of an agreed substantive core of the FOIP idea, becomes relevant. First, this concerns the four main actors the United States, Japan, Australia, and India - as initiators and most consistent proponents of the Indo-Pacific concept. Comparison of their approaches has already allowed us to speak of at least three main pillars of the emerging single concept of 
FOIP, which are (a) ensuring peace and stability; (b) asserting and defending fundamental values; and (c) intensifying cooperation and promoting economic development. This study begins with an introduction, which contains a brief substantiation of the importance of differentiating IPR as a geographic concept and a meaningful concept. The main part of the study is devoted to analysing the practice of current regional interactions of key actors and assessing the prospects for the formation of a common coordinated strategy. In conclusion, it is noted that despite the differences in interpretations of the geographic framework of the IPR, there is every reason to talk about emerging of a new coordinated geopolitical understanding of it represented by the formula "Free and Open Indo-Pacific Region (FOIP)".

Key words: international relations, regionalism, Indo-Pacific region, Free and open Indo-Pacific region, security, economic cooperation, integration, connectedness, USA, Japan, India, Australia, China.

For citing: Pestsov S. K. The concept of a free and open Indo-Pacific region: the common ground in a variety of interpretations // Pacific RIM: Economics, Politics, Law. 2021. V. 24, No 4. P. 111-131. https://doi.org/10.24866/1813-3274/2021-4/111-131.

\section{Введение}

В настоящее время Индо-Тихоокеанский регион (ИТР) всё более очевидно превращается в один из популярных концептов, которые используются для характеристики и описания новых трендов в современной мировой политике. В качестве географического маркера он определяет рамки нового, всё более интегрированного экономического пространства, которое для мира XXI века быстро становится тем, чем было Средиземное море для античной эпохи или Северная Атлантика для XIX и XX веков [39, p. 12]. Одновременно с этим, как и любые другие способы размышления о региональных пространствах, которые, как справедливо заметил М. Бисон, всегда гораздо теснее связаны с политикой, нежели с географией, данный концепт подразумевает особый подход к геополитическому и геоэкономическому упорядочению соответствующего пространства. В этом качестве он объединяет континентальные и морские зоны Индийского и Тихого океанов «в единый континуум, в котором великие и региональные морские державы проецируют свои стратегические программы и формулируют цели, риски и выгоды, которые определяют и формируют национальные геостратегии» [24, p. 9]. ИндоТихоокеанский регион, таким образом, одновременно укрепляет и отрицает географию: он укрепляет её, соединяя Индийский и Тихий океаны; и отрицает, дискурсивно помещая в центр региона далекую Америку и её периферийных и морских азиатских союзников, с одной стороны, и маргинализируя географически находящийся в центре Китай, с другой [39, p. 7]. 
Хотя Индо-Тихоокеанский регион всё ещё остается спорным в обоих смыслах - как географический термин и содержательная концепция, в более актуальный предмет обсуждения он превращается, выступая во втором своём качестве. В этом случае он предстаёт в виде многочисленных вариаций «Свободного и Открытого Индо-Тихоокеанского региона (FOIP), являющихся манифестами разных акторов относительно их видения региона, своего места в нём, того, как регион должен развиваться и с какими государствами они намерены взаимодействовать для достижения своих целей $[7$, p. 46]. Степень общности и согласованности, характеризующая эти видения, позволяет оценить вероятность того, трансформируется ли ИТР в соответствии с объективными процессами геоэкономической динамики в реальное региональное пространство хозяйственной кооперации и межкультурного взаимодействия, или же превратится в новый географический театр стратегического соперничества и конкуренции.

\section{Свободный и открытый Индо-Тихоокеанский регион: общее в многообразии взглядов}

Пройдя с 2007 г. через три «дискурсивные волны, Индо-Тихоокеанский регион ныне приобрёл статус официального термина, принятого большей частью игроков очерчиваемого им регионального пространства [21, p. 151]. Появление термина «Индо-Тихоокеанский регион» в официальных документах Японии, Индии, Австралии, США, АСЕАН, Великобритании, Франции, Германии и ЕС, свидетельствующее о его формальном признании, вовсе не означает отсутствия различий в его понимании и интерпретации. Пока что этот термин, скорее, используется для обозначения не во всём совпадающих, а иногда даже расходящихся концепций, отражающих индивидуальные видения предпочтительного регионального порядка. Основные точки расхождения, чаще всего, связаны (а) с определением пределов расширения и пространственных рамок Индо-Тихоокеанского региона, (б) с основными целями, которые в каждом случае обусловливают такой подход, (в) с определением проблем и сфер активности, требующих наибольшего внимания, (г) с предпочтениями в отношении двусторонних, мини- или многосторонних подходов к организации экономического сотрудничества и обеспечения безопасности и, наконец, (д) с вопросом включения или исключения Китая [13]. Последний остается наиболее дискуссионным, учитывая, что если в подходе США ИТР очевидно выступает средством явного размежевания с Китаем, то для многих других такое противопоставление далеко не всегда является приемлемым. Хотя, при этом, адекватного ответа на вызывающий всё большие опасения подъём Китая ни у одного регионального игрока до сих пор нет.

В этой связи следует согласиться с тем, что общая стратегия FOIP может рассматриваться как инициатива, находящаяся в начальной стадии формирования и 
реализации, имеющая пока что больше недостатков, которые нужно исправить, чем достоинств, которые можно приветствовать [34, p. 39]. Её дальнейшее развитие и содержательное наполнение будут определять результаты взаимодействий множества вовлечённых в процесс регионального строительства акторов, прежде всего США, Японии, Австралии и Индии, как инициаторов и наиболее последовательных сторонников концепции Индо-Тихоокеанского региона.

Чрезвычайно важным становится ответ на вопрос о наличии общих черт, позволяющих говорить о формировании общего содержательного ядра, при всех различиях национальных интерпретаций идеи Свободного и Открытого ИндоТихоокеанского региона (FOIP) этими четырьмя акторами. Ответом в данном случаe, скорее, будет да, нежели нет. И тот факт, что какой-то из компонентов, составляющих эту концепцию, в большей степени поддерживается одним участником (безопасность для США), а другой или другие отдают предпочтение иному (экономика для Японии или инклюзивность для Индии) вовсе не препятствует, как это часто считается, рождению коллективного подхода, а, напротив, содействует этому, помогая согласовать возникающие на этом пути противоречия. Несмотря на то, что за идеей Индо-Тихоокеанского региона могут стоять разные мотивы и интересы, участники отдают себе отчёт в необходимости и важности «упаковать» их в общее видение и согласованную стратегию. Уже сегодня с некоторым основанием речь можно вести, как минимум, о трёх основных столпах формирующейся согласованной концепции FOIP. Ими являются (а) обеспечение мира и стабильности; (б) утверждение и защита фундаментальных ценностей; (в) интенсификация сотрудничества и содействие экономическому развитию. Приоритеты разных участников относительно данных направлений совместных усилий, как уже говорилось, могут отличаться, но практически никто не отрицает значимости каждого из них [12, p. 20].

\section{Безопасность}

Проблематика безопасности и обеспечение стабильного баланса сил до сегодняшнего дня остаётся основным фокусом дискуссий вокруг ИТР. Важными целями в области безопасности, определяемыми разными национальными концепциями FOIP, выступают укрепление национальной безопасности и обороны, обеспечение мира и стабильности, урегулирование имеющихся конфликтов и недопущение их решения с помощью насилия, противодействие нетрадиционным угрозам, таким как терроризм или пиратство.

Наиболее явно проблема региональной безопасности присутствует в видении США, где она тесно связывается с позицией и поведением Китая [17; 38; 18; 32]. Три основных измерения - готовность, партнёрство и продвижение сетевого региона - выступают с точки зрения министерства обороны этой страны главными измерениями индо-тихоокеанской политики. «Готовность» понимается как всеобъемлющая модер- 
низация вооруженных сил для обеспечения долгосрочного влияния США в регионе. «Партнёрство» предполагает укрепление существующей системы двусторонних военных союзов с азиатскими государствами и расширение этой системы за счёт более тесного сотрудничества со старыми и новыми партнёрами. «Продвижение сетевого региона» включает укрепление архитектуры сетевой безопасности с целью поддержания международного порядка, основанного на правилах [17, p. 1].

Однако это не означает, что проблемы безопасности, также чаще всего так или иначе связанные с Китаем, не важны для многих других региональных игроков. Для Индии они актуализуются конфликтом по поводу границ штата АруначалПрадеш и китайской «нитью жемчуга» в Индийском океане, для Японии - спором по поводу островов Сенкаку / Дяоюйдао и китайской военной активностью в Южно-Китайском море, для Индонезии - китайскими претензиями на острова Натуна, для Филиппин, Вьетнама, Малайзии, Брунея - конфликтом вокруг островов архипелага Спратли, для Австралии - расширением влияния Китая в некоторых островных государствах южной части Тихого океана. Всё это не позволяет рассматривать данную сферу исключительно в контексте противостояния и взаимного сдерживания США и Китая.

В качестве одной из основ формирующейся архитектуры безопасности в ИТР часто упоминается «Quad», группировка в составе четырёх стран, появившаяся в 2004 г. как инструмент координации гуманитарных инициатив и оказания помощи после разрушительного цунами в Индийском океане. В 2017 году, после длительного перерыва, сторонами было принято решение о возобновлении её деятельности и возможной трансформации этого объединения в «Quad-Plus» с включением Beликобритании и Франции [48, p. 1-15]. Эта структура, уровень взаимодействия которой в 2019 г. был повышен до министерского, определяется как «слабое геостратегическое объединение государств, обеспокоенных потенциальным вызовом Китая их интересам» [14], способное стать институциональным ядром FOIP.

Одновременно с этим наблюдается интенсификация взаимодействий в области безопасности на двустороннем уровне. Центральным элементом этих взаимодействий всё чаще становится Индия. В 2016 г. она была определена в качестве главного оборонного партнёра США [20]. В 2018 г. оборонное сотрудничество между двумя странами было повышено до уровня постоянного диалога министров иностранных дел и обороны в формате 2+2 [22]. Ранее аналогичный формат приобрело взаимодействие Индии с Японией, недавно такая же договорённость была достигнута с Австралией [36]. В последние годы партнёрами по «Quad» подписано множество соглашений, призванных расширить сотрудничество в области безопасности и повысить его качество. Первоначальные основы были заложены Совместной декларацией Австралии и Японии о сотрудничестве в области безопасности (JDSC) 2007 г. Аналогичное соглашение в 2008 г. было подписано Японией и Ин- 
дией, а ещё через год - Индией и Австралией. В течение 2016-2018 гг. ряд договорённостей, способствующих качественному совершенствованию оборонной кооперации, был достигнут между Индией и США. В их число вошли Меморандум о соглашении по обмену материально-техническими средствами (LEMOA), предоставляющий доступ к военным объектам друг друга для дозаправки и пополнения запасов; Соглашение о совместимости и безопасности коммуникаций (COMCASA), облегчающее доступ к передовым системам обороны; Соглашение о приобретении и перекрёстном обслуживании (ACSA), позволяющее обеспечить обмен материалами и боеприпасами [12]. Некоторые из подобного рода соглашений Индией также уже подписаны или планируются к подписанию с Австралией и Японией [16; 30]. В частности, в 2018 г. Индией были начаты переговоры с Японией по соглашению, которое позволило бы индийскому флоту получить доступ к японской базе в Джибути. Взамен японским военным будет разрешено использовать военные объекты Индии на Андаманских и Никобарских островах [22, p. 12].

Одновременно с этим расширяется и практика военной кооперации в форме совместных военно-морских маневров, учений и операций. Наиболее важными среди них является серия индийско-американских маневров MALABAR, начало которым было положено еще в 1992 г. Некоторые аналитики определяют эти учения как платформу для оборонных действий в Индо-Тихоокеанском регионе в целом, потенциально способную повысить оперативную совместимость военныхединомышленников в морской сфере [29]. Япония присоединялась к участию в этих маневрах в 2007, 2009 и 2014 гг., а с 2015 г. стала постоянным их участником [27]. Данное обстоятельство вместе с намерением расширить содержательный охват учений, с включением кибер- и космической сфер, превращает их в важный элемент коллективного обеспечения региональной безопасности [35, p. 37]. Параллельно в 2015 г. состоялись первые индийско-австралийские морские учения AUSINDEX в Бенгальском заливе. Ещё через год были проведены двусторонние маневры сил специального назначения. В 2018 г. Индия и Япония возобновили после пятилетнего перерыва военно-морские маневры JIMEX. В этом же году состоялись первые контртеррористические учения с участием японских сил самообороны и индийской армии [22, p. 8].

\section{Защита фундаментальных ценностей}

Наряду с вполне очевидной задачей укрепления национальной безопасности, важной целью военного, прежде всего военно-морского, сотрудничества выступает продвижение и утверждение фундаментальных ценностей, к каковым, по общему признанию, относятся верховенство закона в море и свобода судоходства. Смысл первого, как отметил в 2014 г. премьер-министра Японии Синдзо Абэ, заключается 
в том, что (а) государства должны делать и разъяснять свои претензии на основе международного права; (б) государства не должны использовать силу или принуждение, выдвигая свои претензии, и (в) государства должны стремиться к урегулированию споров мирными средствами [41]. Принцип свободы судоходства, как он зафиксирован в Конвенции ООН по морскому праву 1982 г., включает «свободу передвижения судов, свободу захода в порты и использования заводов и доков, для погрузки и разгрузки товаров, а также для перевозки грузов и пассажиров» [44]. Одним из инструментов утверждения этого принципа в регионе стали операции США по обеспечению свободы судоходства (FONOP) и ограничению претензий Китая в Южно-Китайском море, частота которых значительно возросла одновременно с приглашением к их проведению других заинтересованных сторон (Великобритания) при администрации Д. Трампа [42, p. 9]. Конечным результатом в этом случае выступает так называемое «коллективное общественное благо на море (CPGS), обеспечиваемое «позитивной» военно-морской активностью: от борьбы с пиратством и терроризмом, поиска и спасения на море (SAR) до гуманитарных миссий и ликвидации последствий стихийных бедствий (HADR) [11, p. 32]. До последнего времени усилия в этом направлении опирались, главным образом, на односторонние действия США в рамках Инициативы по защите от распространения (PSI) [40; 10], Региональной инициативы по безопасности на море (RMSI) [15] и концепции «Флота тысячи кораблей» (TSN), сформулированной еще в 2005 г. [46, p. 205; 45, p. 68-69]. Сегодня, как полагают многие, всё более ограниченные возможности США требуют расширения поддержки CPGS со стороны региональных партнёров. На это же указывают пришедшая на смену TSN Инициатива «Глобального морского партнёрства» (GMP) и Морская стратегия США 2007 г. [1].

Понимание важности укрепления нетрадиционного сотрудничества в области безопасности среди региональных партнёров США нашло своё воплощение в ряде документов, начало которым было положено Совместной декларацией Японии и Австралии о сотрудничестве в области безопасности 2007 г. За этим последовали Совместная декларация о сотрудничестве в области безопасности между Японией и Индией» (2008), Совместное заявление о расширении глобального сотрудничества и сотрудничества в области безопасности между Австралией и Республикой Корея (2009) и «Совместная декларация о сотрудничестве в области безопасности между Австралией и Индией» (2009). Объём и элементы сотрудничества в области безопасности, сформулированные в этих декларациях, весьма схожи, что подчёркивает реальность стремления Японии, Австралии, Индии и Южной Кореи к углублению партнёрства средних держав [50, p. 15]. Последнее приобретает особую актуальность в свете заметно усилившихся при президенте Д. Трампе сомнений в устойчивости и надёжности американской региональной политики. 
Экономическое развитие. Важное место во всех вариантах концепции FOIP уделяется проблематике развития и расширения экономических взаимодействий на двустороннем и групповом уровне, что рассматривается как крайне важное условие, необходимое для превращения Индо-Тихоокеанского региона в жизнеспособную региональную систему. Этому, во-первых, призвано содействовать укрепление двусторонних хозяйственных взаимодействий между предполагаемыми партнёрами. Пример активно развивающихся в последние годы такого рода взаимодействий демонстрируют отношения Индии и Японии. Товарооборот между двумя странами стал быстро расти после подписания японско-индийского соглашения о всеобъемлющем экономическом партнёрстве (ЕРА) в 2011 г. Очередным толчком, содействующим расширению хозяйственной кооперации, стала Токийская декларация о специальном стратегическом и глобальном партнёрстве Японии и Индии (2014). Кроме всего прочего, Индия в настоящее время остаёся одним из главных получателей японской помощи развитию (ODA) [33, p. 116].

Важным направлением FOIP, непосредственно связанным с экономическим развитием, являются индивидуальные и коллективные усилия в области инфраструктурного строительства и обеспечения связанности. Подход Японии опирается на проект, который получил название «Инициатива в области инвестиций в качественную инфраструктуру» и реализуется с 2016 года ${ }^{1}$. Основная его идея состоит в повышении уровня финансирования для создания конкретных инфраструктурных объектов в Индо-Тихоокеанском регионе, которые отличает высокий уровень качества. Это связано с тем, что, согласно японскому плану, «качественная инфраструктура формирует основы экономического роста страны», а «укрепление связанности между нациями и регионами [представляет собой] основу мирового экономического роста» [31]. В рамках инициативы «Партнёрство по качественной инфраструктуре», одобренной правительством Синдзо Абэ, принято решение о выделении Японией 200 млрд долл. на проекты от Африки до южной части Тихого океана. Предлагаемые Японией проекты «качественной инфраструктуры» призваны создать для государств региона более справедливую, прозрачную, эффективную и устойчивую альтернативу китайским инфраструктурным проектам [43]. Примерами таких проектов являются экономический коридор, соединяющий Вьетнам, Лаос, Таиланд,

\footnotetext{
${ }^{1}$ Пять принципов японской инициативы по инвестированию в инфраструктуру качества включают: (1) «Обеспечение эффективного управления, надежной работы и экономической эффективности с учётом стоимости жизненного цикла, а также безопасности и устойчивости к стихийным бедствиям, терроризму и рискам кибератак; (2) Обеспечение создания рабочих мест, наращивания потенциала и передачи опыта и ноу-хау для местных сообществ; (3) Устранение социальных и экологических последствий; (4) Обеспечение соответствия экономическим стратегиям и стратегиям развития, включая изменение климата и окружающую среду, на национальном и региональном уровнях; и (5) Повышение эффективности мобилизации ресурсов...» [9].
} 
Мьянму, и коридор, связывающий Хошимин на юге Вьетнама и Давэй в Мьянме $[13$, p. 19]. Одновременно с этим Япония подключается и к многосторонним инфраструктурным инициативам. В 2017 г. Японским банком международного сотрудничества (JBIC) был подписан меморандум о взаимопонимании и сотрудничестве в области финансирования инфраструктуры с американской Корпорацией зарубежных частных инвестиций (OPIC) [42, p. 10]. Один из будущих совместных проектов предполагает прокладку подводного кабеля, соединяющего Австралию, ПапуаНовую Гвинею и Соломоновы острова [6]. В конце 2019 г. Япония также объявила о своём намерении участвовать в Азиатской стратегии связанности ЕС [13, p. 19]. В ноябре 2019 г. на полях саммита АСЕАН Япония, США и Австралия объявили о начале реализации «Инициативы Голубых точек» [23]. Трёхстороннее сотрудничество в области инфраструктуры акцентирует внимание на качестве («глобальный золотой стандарт»), прозрачности, устойчивости, участии частного сектора, борьбе с уклонением от долгов - в противовес аналогичным проектам Китая, критикуемым, в частности, за создание ими долговых ловушек и нарушение всех названных стандартов [47]. Активно включается в партнёрства в области инфраструктуры в рамках концепции Индо-Тихоокеанского региона и Индия. Чаще других она кооперируется с Японией в реализации соответствующих проектов в Индийском океане. Одним из наиболее важных среди них является коридор экономического роста Азия - Африка, который, как и связывающий Индию с Россией и Ираном коридор Север - Юг, задуман в качестве альтернативы BRI [37].

Другим важным направлением стимулирования экономической активности в регионе стал поиск новых инициатив сотрудничества, расширение помощи развития не только в рамках государственных программ, но и путём мобилизации частных капиталов. Целый ряд специальных проектов, призванных укрепить роль Соединенных Штатов как страны-донора в Азии и предоставить альтернативу китайским инициативам в области развития, был разработан в период президентства Д. Трампа. Главными среди них стали Акт о более эффективном использовании инвестиций, способствующих развитию (Акт BUILD) и Акт об Азиатской инициативе по обеспечению гарантий (ARIA). Первым предусматривается создание Международной финансовой корпорации развития США (IDFC), призванной более эффективно координировать кредитование развивающихся стран, особенно в Азии и Африке, предоставляя альтернативы «государственным инициативам, которые связаны со скрытыми условиями» [5]. Второй позволяет правительству тратить до 1,5 млрд долл. в год для реализации ряда задач, связанных с концепцией FOIP, включая развитие оборонного потенциала американских партнёров или продвижение демократии [3].

Другие инициативы в области развития, такие как «Содействие развитию и росту за счёт энергии» (Asia EDGE) и Индо-Тихоокеанский деловой форум (IPBF), ори- 
ентированы на повышение роли американских инвесторов в регионе в таких геополитически важных областях, как энергетика и инфраструктура, а также улучшение координации политики правительства США с интересами американского бизнеса [28]. Ещё один недавний проект - Сеть инфраструктурных транзакций и помощи (ITAN) - предназначен для поддержки региональных инициатив в области инфраструктуры и установления связанности, создавая, таким образом, ещё одну альтернативу BRI азиатским странам. B рамках ITAN был создан Консультативный фонд по сделкам (TAF), для помощи азиатским партнёрам в оценке финансового воздействия и экологических последствий инфраструктурных мер [2, р. 15]. Программа, названная «Тихоокеанское обещание», включает план увеличения вдвое объёма финансирования правительством США на цели развития тихоокеанских государств в течение следующих нескольких лет. План также предусматривает расширение присутствия Агентства США по международному развитию (USAID) в Западной части Тихого океана. Одновременно в рамках Азиатского банка развития (АБР) был учреждён американский Фонд инфраструктуры Тихоокеанского региона (PRIF), основной целью которого определено содействие финансированию инфраструктурных мероприятий в Тихоокеанском регионе. Наконец, новое Партнёрство по электрификации Папуа - Новой Гвинеи (PЕР) с участием Австралии, Японии и Новой Зеландии призвано коренным образом улучшить ситуацию с энергоснабжением в этой стране [2, p. 11]. Япония, со своей стороны, следуя приоритетам стратегии FOIP, также приняла решение об увеличении с 2016 г. своих фондов развития - в некоторых случаях довольно существенно - для реализации экономических проектов в странах западной и южной части Тихого океана, Юго-Восточной и Южной Азии, а также Африки [19].

\section{Заключение}

Индо-Тихоокеанский регион как идея в преобладающем большинстве случаев неразрывно связывается с ростом Китая и соперничеством великих держав за региональную гегемонию. «Эта геополитическая навязчивая идея не только затемняет широкое региональное сотрудничество и транснациональные проблемы безопасности человека, такие как бедность, голод, общественное здравоохранение, оборот стрелкового оружия и наркотиков, ухудшение состояния окружающей среды и стихийные бедствия в регионе, но также ... усугубляет существующие опасения, недоверие и дилеммы безопасности» [26, p. 464]. Другой распространенный и столь же сомнительный тезис представлен утверждениями об отсутствии у ИндоТихоокеанского региона каких-либо реальных перспектив, поскольку ключевые страны далеко не во всём согласны с тем, что означает эта идея, а «множественность представлений о Индо-Тихоокеанском регионе, выдвигаемых различными странами, подчёркивает их принципиальную неспособность договориться» [25]. «...Как и в большом доме, построенном на неустойчивом грунте, - констатирует в 
этой связи один из китайских специалистов, - эта схема лишена реальных корней и общих интересов и поэтому не может реализоваться [49, p. 1, 9].

Следует, однако, признать, что Индо-Тихоокеанский регион, не являясь новой или исключительно американской идеей, представляет собой вариант жизнеспособного определения широкого регионального пространства в ситуации меняющегося геоэкономического и геостратегического окружения. Появление этого термина, подчёркивает Раджа Мохан, является сигналом о начале нового этапа. Вопреки «широко распространенному мнению, что географические понятия постоянны», фактически «политическая география меняется в зависимости от политических обстоятельств». Как и люди, сказал он, регионы рождаются, растут и умирают, а в Юго-Восточной Азии, Восточной Азии и Южной Азии появляются новые концепции [8]. Точно так же Индо-Тихоокеанский регион не нацелен на полное исключение Китая, хотя фактор растущей силы и влияния последнего с неизбежностью оказывает влияние на содержательные интерпретации и развитие этой идеи [4, p. 81].

Даже если географический охват Индо-Тихоокеанского региона может поразному пониматься каждым государством, их усилия, связанные с содержательным определением и наполнением этого понятия, свидетельствуют о начале рождения нового согласованного геополитического понимания Индо-Тихоокеанского региона и его трансформации в конкретные варианты политик, рассматривающих два океана как единое пространство безопасности и экономического роста. Это понимание, представленное формулой «Свободного и открытого Индо-Тихоокеанского региона (FOIP)», всё ещё не совпадает во многих конкретных аспектах и приоритетах. Тем не менее, основные положения этой формулы - такие, как порядок, основанный на правилах, с принципами свободной торговли и свободы судоходства; экономическое процветание за счёт инфраструктурной связанности и гармонизации глобальных стандартов и правил; мир и безопасность за счёт расширения сотрудничества в сфере безопасности получают всё более широкое признание и поддержку.

\section{Список источников}

1. A Cooperative Strategy for 21st Century Seapower. Committee on Armed Services House of Representatives. December 13, 2007. P. 77-92. - URL: https://www.govinfo.gov/content/pkg/CHRG-110hhrg44078/pdf/CHRG110hhrg44078.pdf (дата обращения: 12.08.2021).

2. A Free and Open Indo-Pacific. Advancing a Shared Vision. U.S. Department of State. November 4, 2019. P. 15. - URL: https://www.state.gov/wp-content/uplo ads/2019/11/Free-and-Open-Indo-Pacific-4Nov2019.pdf (дата обращения: 12.08.2021).

3. Asia Reassurance Initiative Act of 2018. December 31, 2018. - URL: https://www.congress.gov/115/plaws/publ409/PLAW-115publ409.pdf (дата обращения: 12.08.2021). 
4. Avdaliani, E. Biden's approach to the Indo-Pacific // BESA Center Perspectives Paper. - 2020. - No. 1, 883, January 13. - URL: https://besacenter.org/biden-indopacific-policy/ (дата обращения: 10.08.2021).

5. Bhavan, Jaipragas. Trump strikes a blow in US-China struggle with build act to contain Xi's Belt and Road // South China Morning Post. - 2018. - 20 October. - URL: https://www.scmp.com/week-asia/geopolitics/article/2169441/trump-strikes-blow-uschina-struggle-build-act-contain-xis (дата обращения: 02.07.2021).

6. Brewster, D. A «Free and open Indo-Pacific» and what it means for Australia // The Interpreter. Lowy Institute. - 2018. - 7 March. - URL: https://www.lowyinstitute.o rg/the-interpreter/free-and-open-indo-pacific-and-what-it-means-australia (дата обращения: 08.07.2021).

7. Canada and the Indo-Pacific: «Diverse» and «Inclusive», not «Free» and «Open» // Asia Pacific Foundation of Canada. - 2020. - September. - P. 1-126.

8. Conley, T. M. The Indo-Pacific is the New Asia // The Interpreter. - 2019. January 28. - URL: https://www.lowyinstitute.org/the-interpreter/indo-pacific-new-asia (дата обращения: 14.07.2021).

9. G7 Ise-Shima principles for promoting quality infrastructure investment // MOFA Go. Jp., 2016. - URL: https://www.mofa.go.jp/mofaj/gaiko/oda/files/ 000160272.pdf (дата обращения: 10.06.2021).

10. Khurana, G. S. Proliferation security initiative: an assessment // Strategic Analysis. - April - June 2004. - Vol. 28, no. 2. - P. 237-248.

11. Khurana, G. S. The Indo-Pacific Region. The emerging geopolitical and security environment / G. S. Khurana. - [S. 1] : Dictus Publishing, 2018. - 212 p.

12. Khurana, G. S. The «Indo-Pacific» Idea: origins, conceptualisations and the way ahead // Indo-Pacific Report 2019. Indo-Pacific Partnership. Realising the benefits of economic and maritime cooperation. - New Delhi: National Maritime Foundation (NMF), 2019. - P. 11-28.

13. Heiduk, F. From Asia-Pacific to Indo-Pacific significance, implementation and challenges / F. Heiduk, W. Gudrun // Stiftung Wissenschaft und Politik : SWP Research Paper. - [S. 1] : German Institute for International and Security Affairs, 9 July 2020. -43 p.

14. Hemmings, J. A reborn quadrilateral to deter China // The Lowy Interpreter. 2017. - November 9. - URL: https://www.lowyinstitute.org/the-interpreter/rebornquadrilateral-deter-china (дата обращения: 07.07.2021).

15. Ho, J. Operationalising the Regional Maritime Security Initiative // IDSS Commentary.18/2004. - 2004. - 27 May. - URL: https://www.rsis.edu.sg/wpcontent/uploads/2014/07/CO04018.pdf (дата обращения: 12.08.2021).

16. India-US Ink Six Agreements, including climate change and terrorism // Indian Express. - 2016. - 8 June. - URL: https:// indianexpress.com/article/india/india-newsindia/india-us-ink-six-agreements-including-climate-change-and-terrorism-2841485/ (дата обращения: 12.08.2021). 
17. Indo-Pacific Strategy Report. Preparedness, partnerships, and promoting a networked region // The Department of Defense. - 2019. - June 1. - URL: https://media.defense.gov/2019/Jul/01/2002152311/-1/-1/1/DEPARTMENT-OF-DEFE NSE-INDO-PACIFIC-STRATEGY-REPORT-2019.PDF (дата обращения: 12.08.2021).

18. Interim National Security Strategic Guidance. March 2021. - URL: https://www.whitehouse.gov/wp-content/uploads/2021/03/NSC-1v2.pdf (дата обращения: 12.08.2021).

19. Japan's International Cooperation // White Paper on Development Cooperation 2017. - Tokyo : Ministry of Foreign Affairs of Japan, 2018. - URL: https://www.mofa.go.jp/policy/oda/page22e_000860.html (дата обращения: 10.08.2021).

20. Joint Statement - United States and India: enduring global partners in the 21 Century. The White House. Office of the Press Secretary. June 07, 2016. - URL: https://obamawhitehouse.archives.gov/the-press-office/2016/06/07/joint-statementunited-states-and-india-enduring-global-partners-21st (дата обращения: 12.08.2021).

21. Kai, He. The Institutionalization of the Indo-Pacific: Problems and Prospects / He Kai, Feng Huiyun // International Affairs. - 2020. - 96. 1. - P. 149-168.

22. Kanti, Bajpai. India and Japan: strategic partners for the 21 st century // India and Japan: Growing Partnership and Opportunities for Co-operation. - Kochi, Kerala (India) : Centre for Public Policy Research, 2019. - P. 3-10.

23. McCawley, P. Connecting the Dots on the Blue Dot Net-work // The Interpreter. Lowy Institute. - 2019. - November 12. - URL: https://www.lowyinstitute.org/theinterpreter/connecting- dots-blue-dot-network (дата обращения: 08.07.2021).

24. The Indo-Pacific: An enlarged perspective / M. Henderson, J. Rogers, A. Hao Yang, J. Huai-Che Chiang. - [S. 1.] : The Henry Jackson Society, 2020. - 36 p.

25. Medcalf, R. Indo-Pacific Visions: giving solidarity a chance // Asia Policy. July 2019. - Vol. 14, no 3. - P. 79-95.

26. Pan, Chengxin. The «Indo-Pacific» and geopolitical anxieties about China's rise in the asian regional order // Australian Journal of International Affairs. - 2014. Vol. 68, no. 4. - P. 453-469.

27. Pandit, R. India, US and Japan to Kick off Malabar Naval exercise tomorrow // The Times of India. - 2014. - July 23. - URL: https://timesofindia.indiatimes.com/ india/India-US-and-Japan-to-kick-off-Malabar-naval-exercise-tomorrow/articleshow/38 931444.cms (дата обращения: 12.08.2021).

28. Phuwit, Limviphuwat. American investors eye energy sector under Asia edge initiative // The Nation. Thailand. - 2019. - June 21. - URL: https://www.nationthaila nd.com/business/30371530 (дата обращения: 12.08.2021).

29. Prashanth, Parameswaran. The Malabar exercise: an emerging platform for Indo-Pacific cooperation? // The Diplomat. - 2016. - June 12. - URL: https://thediplomat.com/2016/06/the-malabar-exercise-an-emerging-platform-for-indopacific-cooperation/ (дата обращения: 12.08.2021). 
30. Singing of Agreements with Other Countries. Government of India (Ministry of Defence) Press Release. 5 February 2018. - URL: www.pib.nic.in/ Pressereleaseshare.aspx?PRID=1519147 (дата обращения: 07.07.2021).

31. Sonoura, Kentaro. Japan's initiatives for promoting quality infrastructure investment. UN General Assembly High-Level Side Event: Promoting quality infrastructure investment. 19 September, 2017. - URL: https://www.mofa.go.jp/ files/000291344.pdf (дата обращения: 12.08.2021).

32. Strategic Competition Act of 2021. 117th Congress 1st Session. To Address issues involving the People's Republic of China. - URL: https://www.foreign.senate.gov/ imo/media/doc/DAV21598\%20-\%20Strategic\%20Competition\%20Act\%20of\% 202021.pdf (дата обращения: 12.08.2021).

33. Swaran, Singh. Quads and triangles locating Japan in India's Act East Policy / Singh Swaran, L. Yamamoto // Global Outlook. A Journal of Global Affairs and Comparative International Development. - Spring 2016. - Vol. 1, no 1. - P. 111-123.

34. Taehwa, Hong. Free and open Indo-Pacific Strategy: accurate diagnosis, imperfect prescription // SNU Journal of International Affairs. - 2018. - Vol. 3, iss. 1. - P. 31-52.

35. Takaaki, Asano. Japan-India relations: toward a special strategic partnership // Japan's Global Diplomacy. Views from the Next Generation / ed. by Yuki Tatsumi. [S. 1.] : Stimson Center, March 2015. - P. 33-41.

36. Tanvi, Madan. The rise, fall, and rebirth of the «Quad» // War on the Rocks. 2017. - November 16. - URL: https://warontherocks.com/2017/11/rise-fall-rebirth-quad/ (дата обращения: 12.08.2021).

37. Aman, T. India and Japan eye the dragon in the room / T. Aman, E. Silverberg // Foreign Policy. - 2019. - 20 November. - URL: https://foreignpolicy.com/2019/11/20/ chinawar-navy-india-japan-eye-dragon-in-the-room/ (дата обращения: 02.07.2021).

38. The elements of the China challenge. The Policy Planning Staff, Office of the Secretary of State. November 2020 (Revised December 2020). - URL: https://www.state.gov/wp-content/uploads/2020/11/20-02832-Elements-of-ChinaChallenge-508.pdf (дата обращения: 12.08.2021).

39. The Indo-Pacific: British and Vietnamese perspectives / ed. by J. Rogers, M. Henderson. - [S. 1.] : The Henry Jackson Society, October 2020. - P. 1-40.

40. The proliferation security initiative: can interdiction stop proliferation? // Arms Control Association. June 2004. - URL: https://www.armscontrol.org/act/200406/features/proliferation-security-initiative-interdiction-stop-proliferation (дата обращения: 12.08.2021).

41. The 13th IISS Asian Security Summit - The Shangri-La Dialogue-Keynote address by Shinzo ABE Prime Minister, Japan. May 30, 2014 // Ministry of Foreign Affairs of Japan. - URL: https://www.mofa.go.jp/fp/nsp/page4e_000086.html (дата обращения: 12.08.2021). 
42. The Trump Administration's «Free and Open Indo-Pacific»: issues for Congress. CRS Report. October 3, 2018. - URL: https://crsreports.congress.gov/ product/pdf/R/R45396 (дата обращения: 14.08.2021).

43. Tomohiro, Osaki. In blow to China, Japan's «Quality Infrastructure» to get endorsement at Osaka G20 // The Japan Times Online. - 2019. - June 25. - URL: https://www.japantimes.co.jp/news/2019/06/25/business/economy-business/blow-chinajapans-quality-infrastructure-get-endorsement-osaka-g20/ (дата обращения: 12.08.2021).

44. United Nations Convention on the Law of the Sea UNCLOS). December 1982. URL: https://www.un.org/depts/los/convention_agreements/texts/unclos/unclos_e.pdf (дата обращения: 10.06.2021).

45. US Foreign Policy in a challenging world. Building order on shifting foundations / ed. by M. Clementi, M. Dian, B. Pisciotta. - [S. 1] : Springer International Publishing AG, 2018. $-406 \mathrm{p}$.

46. Vijay, Sakhuja. Maritime Power in the 21st Century. Strategic transactions China, India and Southeast Asia / Sakhuja Vijay. - Singapore : Institute of Southeast Asian Studies, 2011. - 363 p.

47. Wilson, J. Diversifying Australia's Indo-Pacific infrastructure diplomacy // Australian Outlook. Australian Institute of International Affairs. 16 April 2019. - URL: http://www.internationalaffairs.org.au/australianoutlook/diversifying-australias-indopacific-infrastructure-diplomacy/ (дата обращения: 02.07.2021).

48. Wu, Shicun. Indo-Pacific strategy and China's response / Shicun Wu, Colombage Jayanath. - [S. 1.] : Institute for China-America Studies, October 2019. - 21 p.

49. Wu, Zhenglong. Indo-Pacific NATO: a pipe dream // China-US Focus. - 2020. September 16. - URL: https://www.chinausfocus.com/peace-security/indo-pacific-nato-a-pipedream (дата обращения: 02.07.2021).

50. Yoshihide, Soeya. Japan's Indo-Pacific approach: from China Strategy to middle power diplomacy // QS Subject Focus Summit on politics and international relations power shifts in the Asia-Pacific: large and small states perspectives. - Victoria University of Wellington, February 19-21, 2020. - P. 15. - URL: https://www.academia.edu/ 43238317/Power_Shifts_in_the_Asia_Pacific_Large_and_Small_States_Perspectives_Co nference_Proceedings (дата обращения: 11.06.2021).

\section{Информация об авторе}

С. К. Песцов - доктор политических наук, главный научный сотрудник Центра глобальных и региональных исследований Института истории, археологии и этнографии Дальневосточного отделения Российской академии наук. 


\section{References}

1. A Cooperative Strategy for 21st Century Seapower. Committee on Armed Services House of Representatives. December 13, 2007. Pp. 77-92. Available at: https://www.govinfo.gov/content/pkg/CHRG-110hhrg44078/pdf/CHRG110hhrg44078.pdf (accessed 12 August 2021).

2. A Free and Open Indo-Pacific. Advancing a Shared Vision. U.S. Department of State. November 4, 2019. P. 15. Available at: https://www.state.gov/wpcontent/uploads/2019/11/Free-and-Open-Indo-Pacific-4Nov2019.pdf (accessed $12 \mathrm{Au}$ gust 2021).

3. Asia Reassurance Initiative Act of 2018. December 31, 2018. Available at: https://www.congress.gov/115/plaws/publ409/PLAW-115publ409.pdf (accessed $12 \mathrm{Au}$ gust 2021).

4. Avdaliani E. Biden's approach to the Indo-Pacific. BESA Center Perspectives Paper, 2020, no. 1, 883, January 13. Available at: https://besacenter.org/biden-indopacific-policy/ (accessed 10 August 2021).

5. Bhavan Jaipragas. Trump strikes a blow in US-China struggle with build act to contain Xi's Belt and Road. South China Morning Post, 2018, 20 October. Available at: https://www.scmp.com/week-asia/geopolitics/article/2169441/trump-strikes-blow-uschina-struggle-build-act-contain-xis (accessed 02 July 2021).

6. Brewster D. A. Free and open Indo-Pacific» and what it means for Australia. The Interpreter. Lowy Institute, 2018, 7 March. Available at: https://www.lowyinstitute.org/the-interpreter/free-and-open-indo-pacific-and-what-itmeans-australia (accessed 08 July 2021).

7. Canada and the Indo-Pacific: "Diverse" and "Inclusive", not "Free" and "Open". Asia Pacific Foundation of Canada, 2020, September, pp. 1-126.

8. Conley T. M. The Indo-Pacific is the New Asia. The Interpreter, 2019, January 28. Available at: https://www.lowyinstitute.org/the-interpreter/indo-pacific-new-asia (accessed 14 July 2021).

9. G7 Ise-Shima principles for promoting quality infrastructure investment. MOFA Go. Jp., 2016. Available at: https://www.mofa.go.jp/mofaj/gaiko/oda/files/000160272.pdf (accessed 10 June 2021).

10. Khurana G. S. Proliferation security initiative: an assessment. Strategic Analysis, April - June 2004, vol. 28, no. 2, pp. 237-248.

11. Khurana G. S. The Indo-Pacific Region. The emerging geopolitical and security environment. [S. 1.]: Dictus Publishing, 2018. 212 p.

12. Khurana G. S. The «Indo-Pacific» Idea: origins, conceptualisations and the way ahead. Indo-Pacific Report 2019. Indo-Pacific Partnership. Realising the benefits of economic and maritime cooperation. New Delhi: National Maritime Foundation (NMF), 2019, pp. 11-28. 
13. Heiduk F., Gudrun Wr. From Asia-Pacific to Indo-Pacific significance, implementation and challenges. Stiftung Wissenschaft und Politik: SWP Research Paper. [S. 1.]: German Institute for International and Security Affairs, 9 July 2020. 43 p.

14. Hemmings J. A reborn quadrilateral to deter China. The Lowy Interpreter, 2017, November 9. Favailable at: https://www.lowyinstitute.org/the-interpreter/rebornquadrilateral-deter-china (accessed 07 July 2021).

15. Ho J. Operationalising the Regional Maritime Security Initiative. IDSS Commentary.18/2004, 2004, 27 May. Available at: https://www.rsis.edu.sg/wpcontent/uploads/2014/07/CO04018.pdf (accessed 12 August 2021).

16. India-US Ink Six Agreements, including climate change and terrorism. Indian Express, 2016, 8 June. Available at: https:// indianexpress.com/article/india/india-newsindia/india-us-ink-six-agreements-including-climate-change-and-terrorism-2841485/ (accessed 12 August 2021).

17. Indo-Pacific Strategy Report. Preparedness, partnerships, and promoting a networked region. The Department of Defense, 2019, June 1. Available at: https://media.defense.gov/2019/Jul/01/2002152311/-1/-1/1/DEPARTMENT-OF-DEFENSEINDO-PACIFIC-STRATEGY-REPORT-2019.PDF (accessed 12 August 2021).

18. Interim National Security Strategic Guidance. March 2021. Available at: https://www.whitehouse.gov/wp-content/uploads/2021/03/NSC-1v2.pdf (accessed 12 August 2021).

19. Japan's International Cooperation. White Paper on Development Cooperation 2017. Tokyo: Ministry of Foreign Affairs of Japan, 2018. Available at: https://www.mofa.go.jp/policy/oda/page22e_000860.html (accessed 10 August 2021).

20. Joint Statement - United States and India: enduring global partners in the 21 Century. The White House. Office of the Press Secretary. June 07, 2016. Available at: https://obamawhitehouse.archives.gov/the-press-office/2016/06/07/joint-statementunited-states-and-india-enduring-global-partners-21st (accessed 12 August 2021).

21. Kai He, Huiyun Feng. The Institutionalization of the Indo-Pacific: Problems and Prospects. International Affairs, 2020, 96. 1, pp. 149-168.

22. Kanti Bajpai. India and Japan: strategic partners for the 21st century. India and Japan: Growing Partnership and Opportunities for Co-operation. Kochi, Kerala (India) : Centre for Public Policy Research, 2019, pp. 3-10.

23. McCawley P. Connecting the Dots on the Blue Dot Net-work. The Interpreter. Lowy Institute, 2019, November 12. Available at: https://www.lowyinstitute.org/theinterpreter/connecting- dots-blue-dot-network (accessed 08 July 2021).

24. Henderson M., Rogers J., Hao Yang A., Huai-Che Chiang J. The Indo-Pacific: An enlarged perspective. [S. 1.]: The Henry Jackson Society, 2020. 36 p.

25. Medcalf R. Indo-Pacific Visions: giving solidarity a chance. Asia Policy, July 2019, vol. 14, no 3, pp. 79-95. 
26. Pan Chengxin. The «Indo-Pacific» and geopolitical anxieties about China's rise in the asian regional order. Australian Journal of International Affairs, 2014, vol. 68, no. 4, pp. 453-469.

27. Pandit R. India, US and Japan to Kick off Malabar Naval exercise tomorrow. The Times of India, 2014, July 23. Available at: https://timesofindia.indiatimes.com/ india/India-US-and-Japan-to-kick-off-Malabar-naval-exercisetomorrow/articleshow/38931444.cms (accessed 12 August 2021).

28. Phuwit Limviphuwat. American investors eye energy sector under Asia edge initiative. The Nation. Thailand, 2019, June 21. Available at: https://www.nationthail and.com/business/30371530 (accessed 12 August 2021).

29. Prashanth Parameswaran. The Malabar exercise: an emerging platform for Indo-Pacific cooperation? The Diplomat, 2016, June 12. Available at: https://thediplomat.com/2016/06/the-malabar-exercise-an-emerging-platform-for-indopacific-cooperation/ (accessed 12 August 2021).

30. Singing of Agreements with Other Countries. Government of India (Ministry of Defence) Press Release. 5 February 2018. Available at: www.pib.nic.in/Presserelea seshare.aspx?PRID=1519147 (accessed 07 July 2021).

31. Sonoura Kentaro. Japan's initiatives for promoting quality infrastructure investment. UN General Assembly High-Level Side Event: Promoting quality infrastructure investment. 19 September, 2017. Available at: https://www.mofa.go.jp/files/ 000291344.pdf (accessed 12 August 2021).

32. Strategic Competition Act of 2021. 117th Congress 1st Session. To Address issues involving the People's Republic of China. Available at: https://www.fore ign.senate.gov/imo/media/doc/DAV21598\%20-

\%20Strategic\%20Competition\%20Act\%20of\%202021.pdf (accessed 12 Augus t2021).

33. Swaran Singh, Yamamoto L. Quads and triangles locating Japan in India's Act East Policy. Global Outlook. A Journal of Global Affairs and Comparative International Development. - Spring 2016. - Vol. 1, no 1. - P. 111-123.

34. Taehwa Hong. Free and open Indo-Pacific Strategy: accurate diagnosis, imperfect prescription. SNU Journal of International Affairs, 2018, vol. 3, iss. 1, pp. 31-52.

35. Takaaki Asano. Japan-India relations: toward a special strategic partnership. In: Yuki Tatsumi (ed.). Japan's Global Diplomacy. Views from the Next Generation. [S. 1.]: Stimson Center, March 2015, pp. 33-41.

36. Tanvi Madan. The rise, fall, and rebirth of the «Quad». War on the Rocks, 2017, November 16. Available at: https://warontherocks.com/2017/11/rise-fall-rebirthquad/ (accessed 12 August 2021).

37. Aman T., Silverberg E. India and Japan Eye the Dragon in the Room. Foreign Policy, 2019, 20. Available at: https://foreignpolicy.com/2019/11/20/china-war-navyindia-japan-eye-dragon-in-the-room/ (accessed 02 July 2021). 
38. The elements of the China challenge. The Policy Planning Staff, Office of the Secretary of State. November 2020 (Revised December 2020). Available at: https://www.state.gov/wp-content/uploads/2020/11/20-02832-Elements-of-ChinaChallenge-508.pdf (accessed 12 August 2021).

39. Rogers J., Hendersjn M. (eds.). The Indo-Pacific: British and Vietnamese perspectives. [S. 1.]: The Henry Jackson Society, October 2020, pp. 1-40.

40. The proliferation security initiative: can interdiction stop proliferation?. Arms Control Association. June 2004. Available at: https://www.armscontrol.org/act/200406/features/proliferation-security-initiative-interdiction-stop-proliferation (accessed 12 August 2021).

41. The 13th IISS Asian Security Summit - The Shangri-La Dialogue-Keynote address by Shinzo ABE Prime Minister, Japan. May 30, 2014. Ministry of Foreign Affairs of Japan. Available at: https://www.mofa.go.jp/fp/nsp/page4e_000086.html (accessed 12 August 2021).

42. The Trump Administration's «Free and Open Indo-Pacific»: issues for Congress. CRS Report. October 3, 2018. Available at: https://crsreports.congress.gov/ product/pdf/R/R45396 (accessed 14 August 2021).

43. Tomohiro Osaki. In blow to China, Japan's «Quality Infrastructure» to get endorsement at Osaka G20. The Japan Times Online, 2019, June 25. Available at: https://www.japantimes.co.jp/news/2019/06/25/business/economy-business/blow-chinajapans-quality-infrastructure-get-endorsement-osaka-g20/ (accessed 12 August 2021).

44. United Nations Convention on the Law of the Sea UNCLOS). December 1982. Available at: https://www.un.org/depts/los/convention_agreements/texts/unclos/ unclos_e.pdf (accessed 10 June 2021).

45. Clementi M., Dian M., Pisciotta B. (eds.). US Foreign Policy in a challenging world. Building order on shifting foundations. [S. 1.]: Springer International Publishing AG, 2018. 406 p.

46. Vijay Sakhuja. Maritime Power in the 21st Century. Strategic transactions China, India and Southeast Asia. Singapore: Institute of Southeast Asian Studies, 2011. 363 p.

47. Wilson J. Diversifying Australia's Indo-Pacific infrastructure diplomacy. Australian Outlook. Australian Institute of International Affairs. 16 April 2019. Available at: http://www.internationalaffairs.org.au/australianoutlook/diversifying-australias-indopacific-infrastructure-diplomacy/ (accessed 02 July 2021).

48. Wu Shicun, Jayanath Colombage. Indo-Pacific strategy and China's response. [S. 1.]: Institute for China-America Studies, October 2019. $21 \mathrm{p}$.

49. Wu Zhenglong. Indo-Pacific NATO: a pipe dream. China-US Focus, 2020, September 16. Available at: https://www.chinausfocus.com/peace-security/indo-pacificnato-a-pipe-dream (accessed 02 July 2021).

50. Yoshihide Soeya. Japan's Indo-Pacific approach: from China Strategy to middle power diplomacy. QS Subject Focus Summit on politics and international relations 
power shifts in the Asia-Pacific: large and small states perspectives. Victoria University of Wellington, February 19-21, 2020. - P. 15. - URL: https://www.academia.edu /43238317/Power_Shifts_in_the_Asia_Pacific_Large_and_Small_States_Perspectives_C onference_Proceedings_(accessed 11 June 2021).

\section{Information about the author}

S. K. Pestsov - Doctor of Political Science, Chief Researcher at the Center for Global and Regional Studies of the Institute of History, Archeology and Ethnography, Far Eastern Branch of the Russian Academy of Sciences. 